\title{
Improving Computer Science Instruction and Computer Use for African American Secondary School Students: *
}

\author{
A Focus Group Exploration of Computer Science Identity of African American Teachers \\ Lelia Hampton \\ Computer and Information Sciences \\ Spelman College \\ Atlanta, GA 30314 \\ lhampto4@scmail.spelman.edu \\ Robert Cummings \\ Computer Science \\ Morehouse College \\ Atlanta, GA 30314 \\ robert.cummings@morehouse.edu \\ Kinnis Gosha \\ Computer Science \\ Morehouse College \\ Atlanta, GA 30314 \\ robert.cummings@morehouse.edu
}

\begin{abstract}
As the demand for computing careers increases, it is important to implement strategies to broaden the participation in computer science for African Americans. Computer science courses and academic pathways are not always offered in secondary schools. Many teachers are not trained in computer science, yet are pushed to incorporate more computing, computational thinking, and computer usage. A qualitative focus group study was implemented to assess the computer science identities of African American teachers and of their respective urban secondary schools serving African American students. Three major codes were identified: district administration of computer and computing implementation, teacher attitudes towards computer science instruction, and teachers' recommendations to improve computer science and computational thinking instruction and outreach for African American secondary school students. Findings can be used to improve computer science and technology rollout programs from county and district administrations, teacher instruction with digital tools, and computer science outreach for African American secondary school students.
\end{abstract}

\section{CCS Concepts}

-Applied Computing $\rightarrow$ Education • Computing education $\rightarrow$ Computational thinking Computing education $\rightarrow$ K-12 education.

\section{KEYWORDS}

Computing education; underrepresented minorities; self-efficacy; sense of belonging; computing identity; K-12 education

\section{ACM Reference format:}

Lelia Hampton, Robert Cummings and Kinnis Gosha. 2019. Improving Computer Science Instruction and Computer Use for African American Secondary School Students: A Focus Group Exploration of Computer

Permission to make digital or hard copies of all or part of this work for personal or classroom use is granted without fee provided that copies are not made or distributed for profit or commercial advantage and that copies bear this notice and the full citation on the first page. Copyrights for components of this work owned by others than ACM must be honored. Abstracting with credit is permitted. To copy otherwise, or republish, to post on servers or to redistribute to lists, requires prior specific permission and/or a fee. Requests permissions from Permissions@acm.org.

SIGMIS-CPR '19, 7une 20-22, 2019, Nashville, TN, USA

(c) 2019 Association for Computing Machinery

ACM ISBN 978-1-4503-6088-3/19/06 ...\$15.00

http://doi.org/10.1145/3322385.3322399
Science Identity of African American Teachers. In Proceedings of ACM SIGMIS-CPR '19). ACM, New York, NY, USA, 7 pages. http://dx.doi.org/10.1145/3322385.3322399

\section{INTRODUCTION}

Although computing is an expanding field [1], there is a substantial gap in African Americans pursuing this field as compared to other ethnicities [2, 3]. In 2017, only $3.7 \%$ of computing degrees were awarded to Black or African American students [4]. Research has shown that introducing secondary school students to computer science coursework can increase their likelihood to pursue an undergraduate degree in computer science [6]. Select high school students are offered the Advanced Placement (AP) Computer Science A exam, a standardized course and examination developed to instruct, assess and credit students' skill-level in problem-solving, commonly-used algorithms, data structures, and solution writing in an objectoriented paradigm [6]. However, there are not many African American students taking this course nationwide with no other computing alternative course offered [5]. Many schools with computing courses do not have African American educators teaching these courses. As a result, African Americans tend to not have computing (computer science, computer engineering, and information sciences) experience and exposure prior to postsecondary education. This lack of computing interaction can lead to a low sense of belonging and low or a misinformed selfefficacy in computing [37, 38].

\subsection{Sense of Belonging in Computing}

Social belonging, which is the perception of social connectedness, is a basic human motivation and predicts favorable outcomes $[9,10]$. Belonging uncertainty refers to a state in which "members of socially stigmatized groups are more uncertain of the quality of their social bonds and thus more sensitive to issues of social belonging" in academic and professional settings. Thereby, belonging uncertainty contributes to racial disparities in achievement [10]. In academic and professional settings where certain racial minorities are underrepresented, namely the computing fields, the lack of a sense of belonging can serve as a disadvantage as sense of belonging is critical to intellectual achievement [10]. 


\subsection{Self-efficacy as a Computing Teacher}

According to Bandura, "perceived self-efficacy refers to beliefs in one's capabilities to organize and execute the courses of action required to produce given attainments" [9]. Predominant theories of achievement motivation emphasize the need for selfefficacy [10]. An individual's self-efficacy is largely influenced by people with similar identities performing a behavior successfully; this is termed as "vicarious experience" [11, 12]. Positive teacher self-efficacy beliefs are associated with "positive teaching behaviors and student outcomes" [13]. One study that examined the effect of computing workshops on teachers' selfefficacy found that teachers' self-efficacy improved as a result of the workshops, the enhanced self-efficacy was sustained years after involvement in the workshops, and that augmenting computing workshops with online courses shows a significant difference in some aspects of self-efficacy compared to partaking in the workshop alone [10].

\subsection{Role of Teachers in Broadening Computing Education and Computational Thinking for Students of Color}

There is a need for K-12 teachers to understand problem solving processes as algorithmic and ways in which computational thinking can be used to solve interdisciplinary problems. For example, computational thinking concepts could be integrated into language arts, social studies, science, mathematics, and computer science [14]. In addition, computational thinking can be used to address the lack of accessibility of computing courses by taking advantage of the cross-disciplinary nature of computational thinking and embedding computational thinking across subject areas. Incorporating computational thinking concepts into teaching requires continuous professional development and support which can be done with online learning that also encourages communities of practice where educators can exchange ideas, challenges, solutions, and resources learned from their classroom practice $[15,16]$.

Additionally, in the state of Georgia, county districts have implemented a Business and Computer Science pathway in the state's Career, Technical, and Agricultural Education program. Teachers may be certified to teach this course by fulfilling the requirements, including maintaining membership in relevant professional organizations, providing the required documentation, annually shadowing a business for a minimum of eight hours, and annually partaking in at least twenty hours of professional development activities related to Business and Computer Science such as workshops or college courses [17].

Goode argues that increasing the numbers of students of color studying computer science must begin with the preparation and support of teachers [18]. Secondary school computer science instruction can be extremely labor intensive due to several barriers, including the lack of curriculum for computer science courses, lack of teachers with strong technical backgrounds, and lack of funding for a computer science elective course [18]. In addition, the absence of a professional network of computer science teachers at a school hinders the ability to partake in collaborative lesson planning and a shared community of knowledge. There is a need for more training opportunities on more difficult computing concepts as well $[18,19]$.

Teachers reported a need for outreach and support from university students, including tutoring resources and broadening high school students' scope of the field. University-hosting workshops are encouraged to support secondary school teachers to teach computer science workshops held by universities that emphasize professional development and a professional support network which has been demonstrated to have positive outcomes for teachers [20]. There have been workshops to instruct teachers on computational thinking and computer science principles and how to instruct them through simulations [20]; some workshops even offer stipends for participating teachers [20]. Along with these workshops, another strategy to increase the number of qualified computer science teachers is to develop certification programs that target pre-service teachers $[18,19]$. The results of the intervention demonstrate that teachers have great capability to address low enrollment of students of color in computer science courses and attract students to computer science courses when given professional support and resources.

While other research has explored targeting high school teachers to teach computer science, little research has specifically targeted African American secondary school STEM teachers to implement computing education. Additionally, little research has examined the self-efficacy to teach computing and sense of belonging in computing for African American teachers in a world where African Americans are underrepresented in computing fields.

\section{DESIGN/EXPERIMENT}

\subsection{Participants}

Participants were recruited through voluntary sampling of interested African American secondary school STEM teachers in the Metro Atlanta, GA region. From volunteers, four STEMcertified middle and high school teachers were selected, stratified by school location and student demographic: two teachers were from predominantly Black urban schools and two teachers were from diverse suburban schools. All participants were African American. Three participants were female, and one was male. Their ages ranged from 36-47. Informed consent was obtained from each individual. The participants were compensated for their time with $\$ 250$.

\subsection{Procedure}

Second author facilitated the focus group. The focus group was semi-structured and lasted one hour and fifteen minutes. The focus group allowed the researchers to direct the line of questioning and clarify the experiences of African American teachers and the implementation of computing and computational thinking at secondary schools. The participants were asked about the schools in which they teach, their experiences with computing and computational thinking, their students' attitudes towards computing, their attitudes towards instructing computing and computational thinking at their 
respective schools, and any other recommendations (see Table

1). The focus group was audio recorded and transcribed.

Table 1. Identified codes and their definitions

\begin{tabular}{|c|c|}
\hline Codes & Definitions \\
\hline School Description & $\begin{array}{l}\text { The demographic and technology usage of } \\
\text { the school in which the participant teaches }\end{array}$ \\
\hline $\begin{array}{l}\text { Experience Teaching } \\
\text { Computing }\end{array}$ & $\begin{array}{c}\text { Participants' experience with teaching with } \\
\text { computational thinking and computing }\end{array}$ \\
\hline $\begin{array}{l}\text { School's Computing } \\
\text { Demand }\end{array}$ & $\begin{array}{l}\text { The demand for computing education in } \\
\text { the school in which the participant teaches }\end{array}$ \\
\hline $\begin{array}{l}\text { Importance in Teaching } \\
\text { Computing }\end{array}$ & $\begin{array}{l}\text { Participants' beliefs in the importance of } \\
\text { teaching computing }\end{array}$ \\
\hline $\begin{array}{l}\text { Teacher Attitudes on } \\
\text { Teaching Computing }\end{array}$ & $\begin{array}{l}\text { Participants' attitudes towards technology } \\
\text { use and teaching computer science } \\
\text { including stressors, interest, and } \\
\text { requirements for certification }\end{array}$ \\
\hline $\begin{array}{l}\text { Teacher Attitudes on } \\
\text { Computing }\end{array}$ & $\begin{array}{l}\text { Participants' attitudes towards the field of } \\
\text { computing }\end{array}$ \\
\hline $\begin{array}{c}\text { Teacher Computing Self- } \\
\text { efficacy }\end{array}$ & $\begin{array}{c}\text { Participants' self-efficacy to teach } \\
\text { computing }\end{array}$ \\
\hline $\begin{array}{l}\text { School's Computing } \\
\text { Sense of Belonging }\end{array}$ & $\begin{array}{l}\text { The normalcy and belongingness in which } \\
\text { computing has at the school in which the } \\
\text { participant teaches }\end{array}$ \\
\hline $\begin{array}{l}\text { Perceived Student } \\
\text { Computing Sense of } \\
\text { Belonging }\end{array}$ & $\begin{array}{l}\text { Participants' beliefs of their students sense } \\
\text { of belonging with the field of computing }\end{array}$ \\
\hline $\begin{array}{l}\text { Perceived Student } \\
\text { Mindset and Self- } \\
\text { efficacy }\end{array}$ & $\begin{array}{l}\text { Participants' beliefs of their students' } \\
\text { mindset and self-efficacy to perform in the } \\
\text { field of computing }\end{array}$ \\
\hline $\begin{array}{c}\text { Teacher's } \\
\text { Recommendations }\end{array}$ & $\begin{array}{l}\text { Participants' recommendations to improve } \\
\text { technology use and computing education at } \\
\text { the schools in which they teach }\end{array}$ \\
\hline
\end{tabular}

\subsection{Analysis}

The transcript of the focus group recording was analyzed using direct hybrid inductive-deductive thematic analysis [21]. The code manual was developed using literature suggestions on critical variables restricting the engagement of African American teachers and students into pursuing computing opportunities such as sense of belonging [22] and self-efficacy [9]. The code manual also included the research team's suggestions based on previous interactions with secondary schools for computing outreach programming [23-25]. The authors reviewed the codes answering quality appraisal items determined by Atkins et al. [26]. No additional modifications were required. Data from the transcriptions were summarized into initial themes. The codes from the codebook were applied to the identified themes; additional codes were determined during this process. Themes were compared with each other to determine any links between themes for further summarization and legitimating.

\section{RESULTS}

\subsection{School Environment}

The participants that taught at the predominantly African American schools reported that their schools had low funding and offered students Chromebook laptops to use, with the availability of the laptops being limited: "The system of Chromebook distribution in this school district is not as efficient as it needs to be. So they have not fully reached the potential of having a real one to one classroom setting for every student...I would say the tech at my school is not all that great, particularly talking to the labs. To me those those desktops there are outdated or they're slow. I don't think that the infrastructure for the web services, or internet, wifi is that great. There's a lot of missing parts, maybe mouse, maybe keyboard, maybe buttons, you know just things of that nature." At the diverse schools, students were offered laptops with each student having their own laptop and the availability of an onsite technician to handle IT issues: "We're in a one to one Chromebook situation and are really encouraged to use the technology" "We have people at our fingertips that will help us at a moment's notice at whatever we have going on with the technology.". In agreement, all participants expressed that terms of implementing information technology into the classrooms, their respective schools district administrations battle trade offs between acquiring more computers and adequately funding teachers' salaries: "there's an issue with, how much technology can they really give and spend money towards, and will that still allow them to bring in those educators or retain those educators that they need?". Participants also experienced inconsistent decisions with administrators choosing technologies which inconveniently resulted in changed lesson plans: "for me personally it's a lot of start and stop initiatives like, we're going to push this down the pipeline for teachers to do this, and then boom, it's all of a sudden, we're not going to do that". "What's a pain because instructionally, the teachers and the kids are ready to do one thing, and then they rollout something else."

\subsection{Teaching Computing}

The teachers had no experience teaching computing, but did incorporate computational math and quiz programs and the Spark programming tool: "it's basically around coding and programming and using the URLs to do videos and things like that...it has the coding embedded in it". One teacher used robotics club as computing education outreach. At one of the diverse schools, a computing pathway (plan of course materials similar to a major) for certification in computer science is also available to students: "there's... a dedicated teacher that has already reached that...can deliver it. So I don't see it going away...And the goal has been for our kids to be pathway completers".

The schools generally encouraged teachers and staff to use technology and computational thinking in course instruction and, particularly with the two diverse schools, frequently funded new digital resources: "Yeah, it really depends on who's at the county office level, as to how things are going to go when it comes to technology. If someone is really, if the decision makers have bought into technology and they really are passionate about the kids and the teacher's having it and really being able to use it, then 
you're going to see something better". However, the participants expressed they were required to learn the details of the new tools on their own, outside of a basic training module: "I find that some people who aren't so tech savvy get overwhelmed with going out there and researching. You really have to research". "Our current school district they will throw something on the computer and walk you through a module and you'll answer some questions and then at the end it will go, check yes or no if you completed it. And then you check yes, and look, you passed!...You're certified. It's like, what?".

\subsection{Importance of Teaching Computing}

Participants believed teaching CS was important to develop students into higher level thinkers as well as to better prepare them for careers in the digital direction of society: "I would say expose them to what the future says to. Because honestly if you look around, everything is going automated". When asked about their thoughts on students' lack of experience with computing participants believed students' current level of skill in computing was low (if not in the computer science pathway) as a result of students' lack of interest, students' lack of network of computer scientists, students' lack of exposure, and parents' lack of exposure: "I think a lot of the lack of interest maybe is number one exposure, number two, of course you have student exposure and parent exposure too. Because if you want the students to be interested then you need that parent support. But also, they need to, students need to be able to make connections".

\subsection{Teacher and Perceived Student Attitudes Towards Computing}

Computing was believed to be beneficial to students, though teaching computing could also be a source of stress because it may limited student-teacher interaction, overwhelmed teachers with training and updates, and there was no additional money for desired technologies: "Well, if you're going to make me become this computer scientist and so tech savvy, then why am I not making the money that computer scientists make? You've got to learn those different platforms very quickly, and like my colleague said, and then move on and learn something else. So it becomes, it can overwhelm you". When discussing the requirements to teach the computing pathway, which they reported included a computing degree, computing certification, and work experience in computing, participants believed the requirements were not realistic and did not notice many teachers trying to get certified: "it's just not realistic to me that they have that kind of requirement because if you're in the private sector and you're in computer science you're making way more than a teacher". However, they felt the more computer savvy educators would be interested in using knowledge from the computing pathway to supplement course instruction in their other courses. Participants expressed the desire for pioneering a new training and requirement format for the computing pathway, increasing diversity in the students taking computing courses, and providing stipends or incentives for computing teachers: "So that's something that definitely needs to be addressed at the state level, that you need to take your existing STEM teachers and allow them a pathway, those that are interested, to have some type of coding training and be able to get some kind of endorsement as well". "I wouldn't mind doing training for it, as long as it doesn't impact my original certification, teaching hours, and they would allow some type of paid training during the summer months."

Participants had a range of histories with computing including a typing and basic computer literacy course, a $\mathrm{C}++$ or equivalent programming course, and experience with Dialogflow. The participants were eager to learn computing and computational thinking, especially if it benefitted the classroom. They expressed the desire to attend computing and computational thinking workshops and would partake in self-teaching and research in computing and computational thinking because they enjoyed math: "I'm typically the one who will research or go to work shops and hear various other math based programs that help facilitate learning, so those are the things that I've known or the experience that I've gained from".

In terms of training, participants felt that the modules provided by the district provided inadequate training and believed the training would be sufficient if it was led by a computing professional or expert. When training was not provided, teachers had to learn by doing and non-tech savvy instructors struggled. One participant expressed that they "I pick it up pretty quickly" and another confirmed that "[learning] by doing is what we teach our students to do, and so when we do it as educators, we typically have a better result". One participant explicitly said that they did not think as a computer scientist: "I think I don't always think like a computer scientist, because being a different type of scientist, you know some scientists everything should be black and white. And as a computer scientist that's really not the case".

The level of the schools' computing sense of belonging varied between schools with and without computing offerings. Only one school had a specific computer science pathway. The other diverse school offered the AP Computer Science course. "So certain schools have more aligned computer science courses and other schools may have little hints of computer science within the courses."

In general, participants believed students were in-tune with and can articulate computing use and its benefits and that students can influence parents to see the value in computing. While the computing pathway was not as popular as other pathways, such as the forensics or healthcare pathways, the pathways were usually full and well-received by the students: "Well, from my previous experience, those classes are typically full. Are they as popular as say healthcare science? No".

Outside of the students who choose the computer science pathway, participants believed that their students feel they have little to no choice but to do computing if enforced. Participants believe their students are not necessarily interested in pursuing undergraduate degrees in computing because some get academically burned out by senior year and others have a limited focus in career opportunities: "They're focus is so limited. And I even hear them say, I can't imagine doing four more years of school. They're burned out. And so I think industry needs to come down to the classroom". 


\subsection{Teacher's Recommendations for Broadening Computing Education}

The participants provided several recommendations for broadening computing education. It was suggested that the district offer computing dual enrollment programs with community colleges and identify teachers willing to do computing training. They believed teachers could help by pushing underrepresented students into computing, exposing computing applications through students' interests, and putting

Table 2. Connected codes and summarized themes.

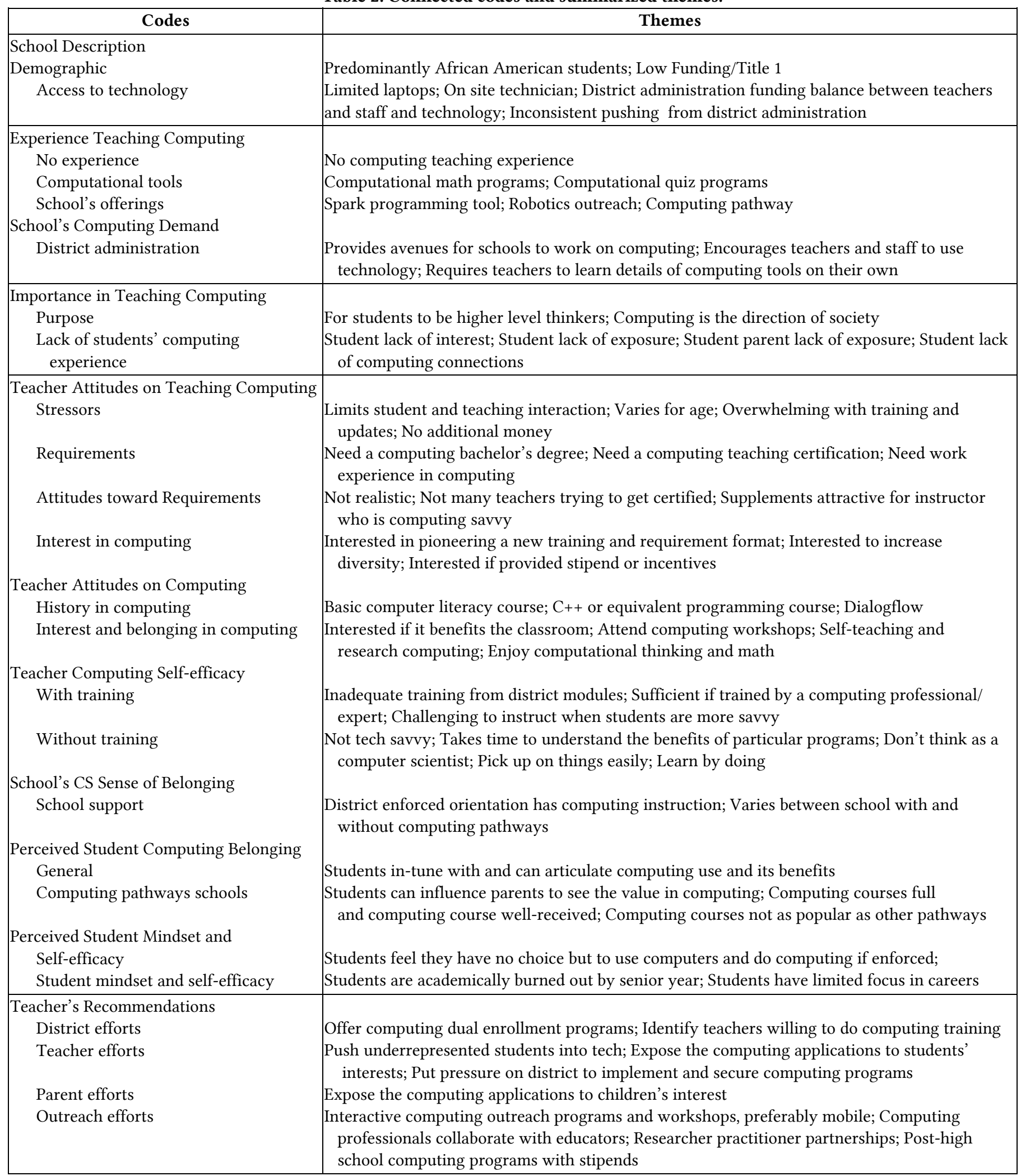


pressure on the district to implement and secure computing programs. They recommended that parents also expose the computing applications through child's interests. They expressed desire for interactive computing outreach programs and workshops that were preferably mobile in order to reach kids outside of the city. It was suggested that the outreach programs include collaboration between computing professionals and educations, partnerships with researchers, and post-high school computing programs with stipends.

\section{DISCUSSION}

The participant teachers' schools matched the descriptions from the literature [6] suggesting many underrepresented minority serving schools have more limited access to technology; however, it doesn't seem to prevent any type of computing or computational thinking instruction. The participating teachers did not have computing teaching experience, however there is promising areas of computing integration particularly in the area of computational thinking $[1,4,39]$. District influence also seems key to integrating more computing into schools. The teachers were supportive in supplementing course material with computing concepts and computational thinking rather than teaching computing. In part, this was because obtaining certification to teach the computing pathway was unrealistic for them and there were no viable options for them to learn enough computing to teach a course. Incorporating computational thinking across the curriculum in lieu of standalone computing has been suggested for schools lacking in resources [1, 4]. Although the teachers expressed their desire to broaden computing education for students of color, as pointed out by Goode, they cannot do so if they are not given the resources to do so [17].

The participating teachers expressed the importance of workshops for teachers and students; it is apparent from previous research that computing workshops have positive outcomes for teacher's [16, 35]. Previous research suggests that computing workshops can increase teacher's self-efficacy [11]. Unfortunately, the district modules were inadequate, and it was easy for participants to pass them without gaining any knowledge. However, teacher's were much more satisfied with the training when they were trained by a computing professional or expert. This suggests that more professional development should be offered to the teachers as a form of support. Teachers expressed their desire for stipends as incentives to teach computing courses. Given the intensive labor of teaching computing [17] and the chronic need for computing teachers to teach students of color [36], stipends could be attractive to potential computing teachers.

This study had some limitations. There was only one focus group conducted. The small sample size of this study means the information collected herein does not provide the best generalizability to a larger population, however the information obtained is still useful in a exploratory sense and in that it draws directly from experiences of educators. During the analysis of the transcripts, the codes were developed from literature and the research team's suggestions without using an established template codebook. Additionally, the measures of self-efficacy and sense of belonging were only asked generally without detail to determine precipitating factors that may have developed or continues to provoke such computing identity factors. Also, the student self-efficacy and sense of belonging is from the perspective of the participating teachers and should be gauged with caution.

\section{CONCLUSION}

The study used a focus group to explore the computer science identities of African American teachers, including their selfefficacy in computing. The information provided by the participants to recruit students and teachers for computing education is notable because it provides valuable advice and insight from experience that can help broaden computing education for students of color. It also demonstrates that teachers from other disciplines, in particular STEM, are willing to teach computing and would like more resources to be able to do so. In addition, they provide insight into the barriers plaguing students of color participation in computing. Through the exploration of their identities and experience in relation to computing, implications of the study for broadening CSE for students of color were discovered. Accessible opportunities for professional development in computing should be presented to teachers who teach students of color, and as suggested, the teachers are eager to learn computing and broaden computing education. Future steps should also be taken to address the barriers that inhibit students of color to receive quality CSE.

\section{ACKNOWLEDGMENTS}

We would like to thank the participant teachers and their respective schools. This research was funded through the National Science Foundation (Grant \#: 1818458).

\section{REFERENCES}

[1] Bureau of Labor Statistics, 2018 Fastest Growing Occupations, United States Department of Labor.

[2] Sharon Lewis, Candace Simon, Renata Uzzell, Amanda Horwitz, and Michael Casserly. 2010. A Call for Change: The Social and Educational Factors Contributing to the Outcomes of Black Males in Urban Schools. Council of the Great City Schools.

[3] Betsy DiSalvo, Mark Guzdial, Charles Meadows, Ken Perry, Tom McKlin, and Amy Bruckman. 2013. Workifying games: successfully engaging african american gamers with computer science. In Proceeding of the 44th ACM technical symposium on Computer science education (SIGCSE '13). ACM, New York, NY, USA, 317-322. DOI: https://doi.org/10.1145/2445196.2445292.

[4] Stuart Zweben and Betsy Bizot. 2017. 2017 CRA Taulbee Survey: Another Year of Record Undergrad Enrollment; Doctoral Degree Production Steady While Master's Production Rises Again. Retrieved from https://cra.org/wpcontent/uploads/2018/05/2017-Taulbee-Survey-Report.pdf.

[5] Andrea Arpaci-Dusseau, Owen Astrachan, Dwight Barnett, Matthew Bauer, Marilyn Carrell, Rebecca Dovi, Baker Franke, Christina Gardner, Jeff Gray, Jean Griffin, Richard Kick, Andy Kuemmel, Ralph Morelli, Deepa Muralidhar, R Brook Osborne, and Chinma Uche. 2013. Computer science principles: analysis of a proposed advanced placement course. In Proceeding of the 44th ACM technical symposium on Computer science education(SIGCSE '13). ACM, New York, NY, USA, 251-256. DOI: https://doi.org/10.1145/2445196.2445273.

[6] College Board. 2016. AP Computer Science A. Retrieved from http://media.collegeboard.com/digitalServices/pdf/ap/ ap-courseoverviews/ap-computer-science-a-course-overview.pdf.

[7] Terrell L. Strayhorn. 2011. Sense of belonging and African American student success in STEM: Comparative insights between men and women. In H. T. Frierson, Jr. \& W. F. Tate (Eds.), Beyond stock stories and folktales: African Americans ' paths to STEM fields (pp. 213-226). New Milford, CT: Emerald Books.

[8] Terrell L. Strayhorn. 2015. Factors influencing black males' preparation for college and success in STEM majors: A mixed methods study. Western fournal of Black Studies 39, 1 (Spring 2015), 45-63. 
[9] Albert Bandura. 1997. Self-Efficacy: The Exercise of Control. New York: Freeman.

[10] Gregory M. Walton and Geoffrey L. Cohen. 2007. A Question of Belonging: Race, Social Fit, and Achievement. fournal of Personality and Social Psychology 92, 1 (2007), 82-96. DOI:http://dx.doi.org/10.1037/0022-3514.92.1.82

[11] Albert Bandura. 1986. Social Foundations of Thought and Action: A Social Cognitive Theory. Englewood Cliffs, NJ: Prentice-Hall.

[12] Peter R. Albion. 1999. Self-Efficacy Beliefs as an Indicator of Teachers' Preparedness for Teaching with Technology. 10th International Conference of the Society for Information Technology \& Teacher Education (SITE 1999).

[13] Robin K. Henson. 2001. Teacher Self-Efficacy: Substantive Implications and Measurement Dilemmas. Annual Meeting of the Educational Research Exchange.

[14] Valerie Barr and Chris Stephenson. 2011. Bringing computational thinking to $\mathrm{K}-12$ : what is involved and what is the role of the computer science education community?. ACM Inroads 2, 1 (February 2011), 48-54. DOI: http://dx.doi.org/10.1145/1929887.1929905

[15] Aman Yadav, Hai Hong, and Chris Stephenson. 2016. Computational thinking for all: Pedagogical approaches to embedding 21st century problem solving in $\begin{array}{lllll}\text { K-12 classrooms. } & \text { TechTrends } & 60, & 6 & \text { (2016), }\end{array}$ DOI:https://doi.org/10.1007/s11528-016-0087-7,

[16] Yadav, C. Stephenson, and H. Hong. Computational thinking for teacher education. Commun. ACM, 60(4):55-62, 2017.

[17] Georgia Department of Education. Business and Computer Science Industry Certification Standards. Retrieved from https://www.gadoe.org/CurriculumInstruction-and-Assessment/CTAE/Documents/BCS-Industry-CertificationStandards-2011-12.pdf.

[18] Joanna Goode. 2007. If You Build Teachers, Will Students Come? The Role of Teachers in Broadening Computer Science Learning for Urban Youth. Journal of Educational Computing Research 36, 1 (2007), 65-88. DOI:http://dx.doi.org/10.2190/2102-5g77-ql77-5506

[19] Joanna Goode. 2010. Connecting K-16 Curriculum \& Policy: Making Computer Science Engaging, Accessible, and Hospitable for Underrepresented Students Proceedings of the 41st ACM Technical Symposium on Computing Science
Education - SIGCSE 10 (2010). DOI:http://dx.doi.org/10.1145/1734263.1734272

[20] Sheikh Iqbal Ahamed, Dennis Brylow, Rong Ge, Praveen Madiraju, Stephen J. Merrill, Craig A. Struble, and James P. Early. 2010. Computational thinking for the sciences: a three day workshop for high school science teachers. In Proceedings of the 41st ACM technical symposium on Computer science education (SIGCSE '10). ACM, New York, NY, USA, 42-46. DOI: https://doi.org/10.1145/1734263.1734277

[21] J. Fereday \& A.E. Muir-Cochrane. (2006). Demonstrating Rigor Using Thematic Analysis: A Hybrid Approach of Inductive and Deductive Coding and Theme Development. International Journal of Qualitative Methods, 5(1).

[22] George Watson. 2006. Technology Professional Development: Long-Term Effects on Teacher Self-Efficacy. Journal of Technology and Teacher Education 14, 1 (2006), 151-165.

[23] Kinnis Gosha, Earl W. Huff Jr., and Jordan Scott. 2018. Computing Career Exploration For Urban African American Students using Embodied Conversational Agents. In Proceedings of the 2018 ACM SIGMIS Conference on Computers and People Research (SIGMIS-CPR'18). ACM, New York, NY, USA, 154-154. DOI: https://doi.org/10.1145/3209626.3209731

[24] Kinnis Gosha and Kamal Middlebrook. 2017. Broadening Participation Research Project: Exploring Computing Careers through a Virtual Career Exploration Fair Using Embodied Conversational Agents (Abstract Only). In Proceedings of the 2017 ACM SIGCSE Technical Symposium on Computer Science Education (SIGCSE '17). ACM, New York, NY, USA, 708-708. DOI https://doi.org/10.1145/3017680.3022425

[25] Kinnis Gosha, Trey Ridley, Ernest Holmes, Kevin Womack, and Jordan Scott. 2017. Introduction to Computer Science for Urban African American Students Using Sphero Robotics Workshop. In Proceedings of the SouthEast Conference (ACM SE '17). ACM, New York, NY, USA, 252-254. DOI https://doi.org/10.1145/3077286.3077323

[26] Salla Atkins, Simon Lewin, Helen Smith, Mark Engel, Atle Fretheim, and Jimmy Volmink. 2008. Conducting a meta-ethnography of qualitative literature: Lessons learnt. BMC Medical Research Methodology 8, 21. 